\title{
Comparison of Micrometeorological Methods used for the Determination of Actual Evapotranspiration
}

Levent ŞAYLAN', Yunus Özkoca ${ }^{2 *}$, Barış Çaldağ ${ }^{1}$, Fatih Bakanoğulları ${ }^{3}$

${ }^{1}$ Ístanbul Technical University, Faculty of Aeronautics and Astronautics, Department of Meteorological Engineering, İstanbul

${ }^{2}$ Antalya Provincial Disaster and Emergency Directorate, Antalya

${ }^{3}$ Atatürk Soil Water and Agricultural Meteorology Research Institute, Kırklareli

\begin{abstract}
Among upmost important effects of climatic variability and change are the related variations in type, amount and timing of precipitation at global or regional scales. This aspect causes different effects from the agricultural point of view. Among these effects the drought phenomenon comes to the forefront. Efforts on eliminating the agricultural drought problem are mainly made by irrigation. That's why the upmost important portion of available water is consumed by agricultural irrigation, globally. Concordantly, the evapotranspiration plays a crucial role on determination of the irrigation water requirement for agriculture and planning the related systems. Usage of the methods on direct measurement of actual evapotranspiration by global means, however; is quite scarce. In this study, the Bowen Ratio Energy Balance and micrometeorological Eddy Covariance Methods, which are widely in use for the measurement of actual evapotranspiration, have been used within the 2009-2010 wheat growing season in Kırklareli. In conclusion, a comparative evaluation of these approaches was done for the advantages and disadvantages by means of their determination abilities of actual evapotranspiration.
\end{abstract}

Key words: Evaporation, Evapotranspiration, Bowen Ratio, Energy Balance, Eddy Covariance

\section{INTRODUCTION}

Evapotranspiration (ET), which can be defined as crop water consumption together with water transfer from open water, soil and vegetation surfaces in gaseous form, is strongly related to the photosynthesis activity, which plays an important role in crop growth. That's why this process effects the plant growth and yield. Evapotranspiration, which is in close interaction with the amount of water, is also seriously affected from meteorological factors. At this point, however; soil and crop factors are to be taken into consideration additionally. Determination of ET is essential to obtain maximum yield and prevent the plants from agricultural drought. Knowing the exact timing and amount of crop water demand enables to plan the corresponding methodologies on related supply and irrigation. Establishment of the related systems and their management can be planned also in this context. By means of consumption currently the major portion of total available water, agriculture takes part in sectors that are expected to be under increasing pressure in the future. To use water appropriately and efficiently, ET; which plays an important role as an output (loss) component of the water budget, should be determined correctly. But the required systems on measurement of the actual ET values are not sufficient especially in developing countries. This circumstance has many reasons. For this reason, crop water consumption is determined rather by calculation. Crop specific coefficients used in these equations are mostly values that are proposed by related international organizations. As a common component of the water and energy balances, satisfactory determination of the ET could enable optimum management of the water and present resources.

Şaylan (2000) determined the energy balance components and actual ET $\left(\mathrm{ET}_{\mathrm{a}}\right)$ values over a soybean field in Grossenzersdorf-Vienna/Austria using the Bowen Ratio Energy Balance (BREB) Method; as mentioned by Özkoca (2015). Todd et. al., (2000) used the BREB and lysimeter methods to determine actual 
evapotranspiration on a grass field in a semiarid and advective region in TexasUnited States. During this study, actual evapotranspiration rates of a weighting type lysimeter were compared with those of the BREB Method for different periods and only little different results were obtained between two approaches (Özkoca, 2015). One of the first studies on the application of the BREB Method on Turkey's conditions were conducted by Ünlü et. al. (2001). This study was on the comparison of the actual water consumption of cotton with corresponding results of the BREB for complete and insufficient irrigation conditions. The results showed that the actual evapotranspiration values from the water balance method and the calculated values using the energy balance approach were close to each other under insufficient irrigation. Results of the complete irrigation application indicated however highly overestimated values for the water budget method, which could be caused by the problems in measurement of deep percolation losses across the parcels. Continuous evapotranspiration and sensible heat flux rates measurements had been done by Wever et. al. (2002) using the Eddy Covariance (EC) Method over a grass surface in Canada-Alberta. Another BREB application was made by Inman-Bamber and McGlinchey in 2003 under environmental conditions of Swaziland and Australia for the growing season of sugar beet. Pauwels and Samson (2006) used the BREB and EC techniques for the measurement of evapotranspiration in Flanders-Belgium. Possible mistakes of the BREB Methodology during drip irrigation were investigated by Soares et. al. (2007) at vineyards in Petrolina-Brasil. Similarly, BREB Method was used by Guo et. al. (2007), Takagi et. al. (2009) and Xing et. al. (2008) in China, Japan and Canada respectively, whereas Shi et al. (2008) and Fritschen (2010) used micrometeorological measurements for the determination of ET in northern China (Changbai Mountain) and Arizona-United States, successively. In this latter study, weighting type lysimeters were used simultaneously to measure actual evapotranspiration. As a result, it was determined that the BREB can indicate daily actual evapotranspiration with a maximum relative error of 5\%; and hence it can be satisfactorily used for latent heat flux of evapotranspiration in short periods and the cumulative values of these periods can also be representative for relatively longer time intervals. Spittlehouse and Black (2010) used BREB and tested its validity for the determination of evapotranspiration in forest areas in Courtenay-Canada. In addition to these; Attarod et. al., (2011), Ünlü et. al., (2010, 2014), Khoomsab and Khummongkol (2011), Bezerra et. al. (2012), Poznikova et. al. (2012), Dicken et. al. (2013), Yan et. al. (2014), Wang et. al. (2014) and Cheng et. al. (2014) calculated ET value by micrometeorological techniques.

Variation in spatial distribution of meteorological variables caused the need for studies at micro scales to obtain reliable results and optimum decision making. Via the acquisition of regional data, micrometeorological studies enable better understanding of regional and global processes. That's why microscale studies are of great importance within meteorological aims (Özkoca, 2015).

Aim of this study is to apply the Bowen Ratio Energy Balance (BREB) and Eddy Covariance (EC) micrometeorological methods on determination and comparison of actual ET (ETa) values over winter wheat crop in Turkey.

\section{Research Field and Measurement Systems}

The research was conducted at the experiment field of Kirklareli Atatürk Soil, Water and Agricultural Meteorology Research Institute Directorate (ASWAM), 
which is adhered to the Ministry of Food, Agriculture and Livestock, General Directorate of Agricultural Research and Policies. The study was a joint the Scientific and Technological Research Council of Turkey (TÜBİTAK) and COST Project between the ASWAM and Meteorological Engineering Department of Istanbul Technical University (İTÜ).

According to the long term (1953-2013) mean climatologic data, Kurklareli City has an average total annual precipitation of $563.5 \mathrm{~mm}$, an average temperature of 13.2 ${ }^{\circ} \mathrm{C}$ and 6 hours insolation (MGM, 2015). Total area of the research field cultivated with winter wheat in this study was ca. 80 da.

A common wheat cultivar was selected by considering the climatological and soil properties of the research region together with the opinions of experts in related area. All of the agricultural activities (pre-sowing procedure, sowing, fertilization, etc.) and related equipment were supplied by the ASWAM. Detailed information on the field studies, soil properties, phenological observations, system establishment, related instruments and sensors can be found in Şaylan et. al. (2012 a,b) and Özkoca (2015).

\section{Bowen Ratio Energy Balance (BREB) and Eddy Covariance (EC) Methods}

As mentioned by Oke (1987), BREB is used to determine the actual evapotranspiration depending upon the distribution ratio of the convective fluxes between the latent heat of evapotranspiration and sensible heat (Özkoca, 2015). This methodology was used for the first time by Bowen to determine the fluxes over free water surfaces in 1926 (Bowen, 1926). Using the BREB Method, latent heat flux of evaporation over a surface can be quantified by considering measurements of temperature and humidity gradients, net radiation and soil heat flux (Fritschen and Simpson, 1989). This is an indirect method used for the measurement of evapotranspiration. It represents a relatively easier approach by means of intelligibility and application when compared with the direct measurement methods. Moreover, it doesn't need any information about surface aerodynamic characteristics and hence, is suitable for global use. Disadvantages of this method are: high sensitivity to the precision of the measuring sensors, need to the length of representativeness (fetch) and extra analysis requirement of the results (Todd et. al., 2000).

Although the BREB method is easier to be applied against the direct measurement techniques, it has also a rather complex structure caused by its numerous calculation steps and data filtering methods.

As mentioned above, this method depends on the measurements of net radiation and soil heat flux together with temperature and humidity gradients between two levels. The BREB method considers the energy balance equation at first (Bowen, 1926).

$$
R_{n}-G=L E+H
$$

Here; $R_{n}$ shows net radiation $\left(W / m^{2}\right), G$ is the soil heat flux $\left(\mathrm{W} / \mathrm{m}^{2}\right)$, LE stands for latent heat flux $\left(\mathrm{W} / \mathrm{m}^{2}\right)$ and $\mathrm{H}$ represents the sensible heat flux $\left(\mathrm{W} / \mathrm{m}^{2}\right)$, respectively.

Put out by Bowen, the method is based on the distribution rate of the incoming energy into $\mathrm{LE}$ and $\mathrm{H}$, namely on the calculation of the Bowen Ratio (Bowen, 1926). This parameter can be calculated as follows:

$$
\beta=\gamma\left[\frac{T_{1}-T_{2}}{e_{a_{1}}-e_{a_{2}}}\right]=\frac{H}{L E}
$$

where; $\beta$ shows the Bowen Ratio, $\gamma$ is the psychrometric coefficient $\left(\mathrm{kPa} /{ }^{\circ} \mathrm{C}\right), \mathrm{T} 1$ is the air temperature at lower level, $\left({ }^{\circ} \mathrm{C}\right), \mathrm{T} 2$ is the air temperature at higher level $\left({ }^{\circ} \mathrm{C}\right)$, eal is the actual vapor pressure at lower level $(\mathrm{kPa})$, and ea2 stands for the actual vapor pressure at higher level $(\mathrm{kPa})$, respectively. 
Once the $\beta$ ratio has been determined, LE $\left(\mathrm{W} / \mathrm{m}^{2}\right)$ can be then calculated using the following equation:

$$
L E=\frac{R_{n}-G}{1+\beta}
$$

Eddy Covariance is a method used for the calculation of gaseous fluxes between the atmosphere and biosphere in the frame of regionally and globally developed flux nets. This method depends on the biases of vertical variations of gases $\left(\mathrm{CO}_{2}\right.$ etc.), temperature and wind velocity from their means (Burba and Anderson, 2013). Components of the method are three dimensional wind speed, $\mathrm{CO}_{2}$, relative humidity and temperature, successively. $\mathrm{CO}_{2}$ and $\mathrm{H}_{2} \mathrm{O}$ fluxes are calculated considering these biases from the mean and atmospheric turbulance. Major advantage of the method is the high measurement sustainability of the corresponding infrared gas analysis sensors (IRGA) with relatively low calibration needs (Şaylan et. al., 2012 b; Özkoca, 2015).

Complete statement of the turbulent flux used for physical calculation of the eddy fluxes contains numerous mathematical approaches and applications. These approaches and statements can be explained generally as mentioned in Burba and Anderson, (2013).

In this frame, the latent heat flux of evapotranspiration is calculated as given below:

$$
L E=\rho_{a} L \overline{w^{\prime} q^{\prime}}
$$

In this equation, LE shows the latent heat flux of evapotranspiration; L stands for latent heat; $q$ is the vertical gradient of water vapour and $\rho_{\mathrm{a}}$ is the density of air $\left(\mathrm{kg} / \mathrm{m}^{3}\right)$; respectively. Detailed information on the application of BREB and EC methods can be found in Şaylan et. al., (2012 a, b) and Özkoca (2015).

\section{Analysis of the BREB Calculations}

To make the results practically usable, required filtration methods were applied on the raw data that were obtained from BREB calculations. Related calculations were done considering the 30-min periods and then the associated daily averages were derived. Following the filtration steps applied on these 30 min-data; daily mean temperature, actual saturation deficit, Bowen Ratio and LE values were re-calculated.

Figure 1 and Figure 2 represent the variations in temperature and vapor pressure deficit during the crop growth season, successively. Similarly; time series of the accordingly calculated Bowen ratios are given in Figure 3. In this way, the obtained Bowen Ratio and other calculated values of the energy balance components were considered to finally assess the required LE values, which are given in Figure 4.

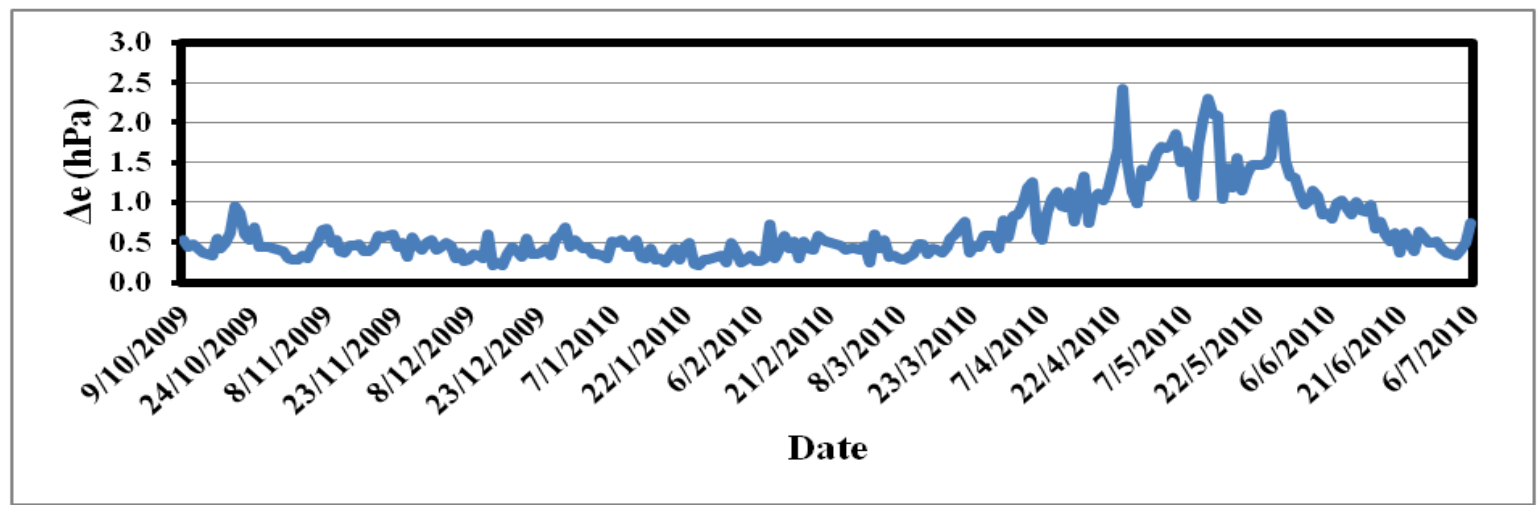

Figure 1: Daily variation of actual water vapour deficits. 


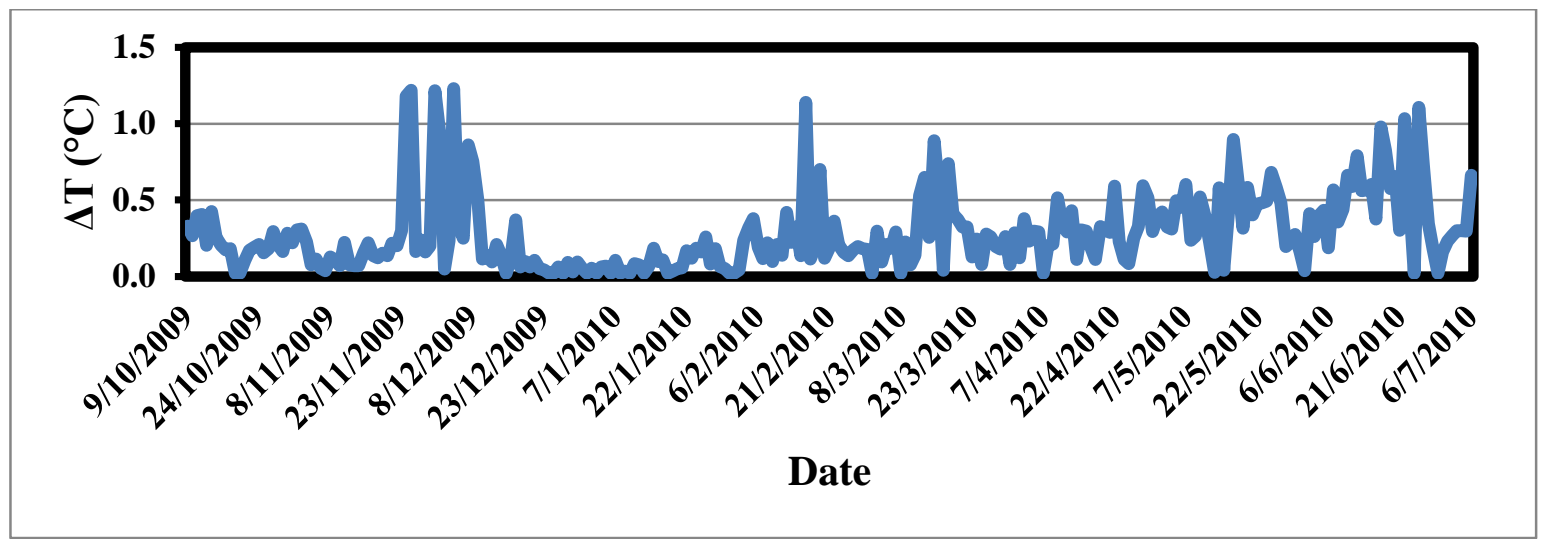

Figure 2: Daily variations in temperature gradients.

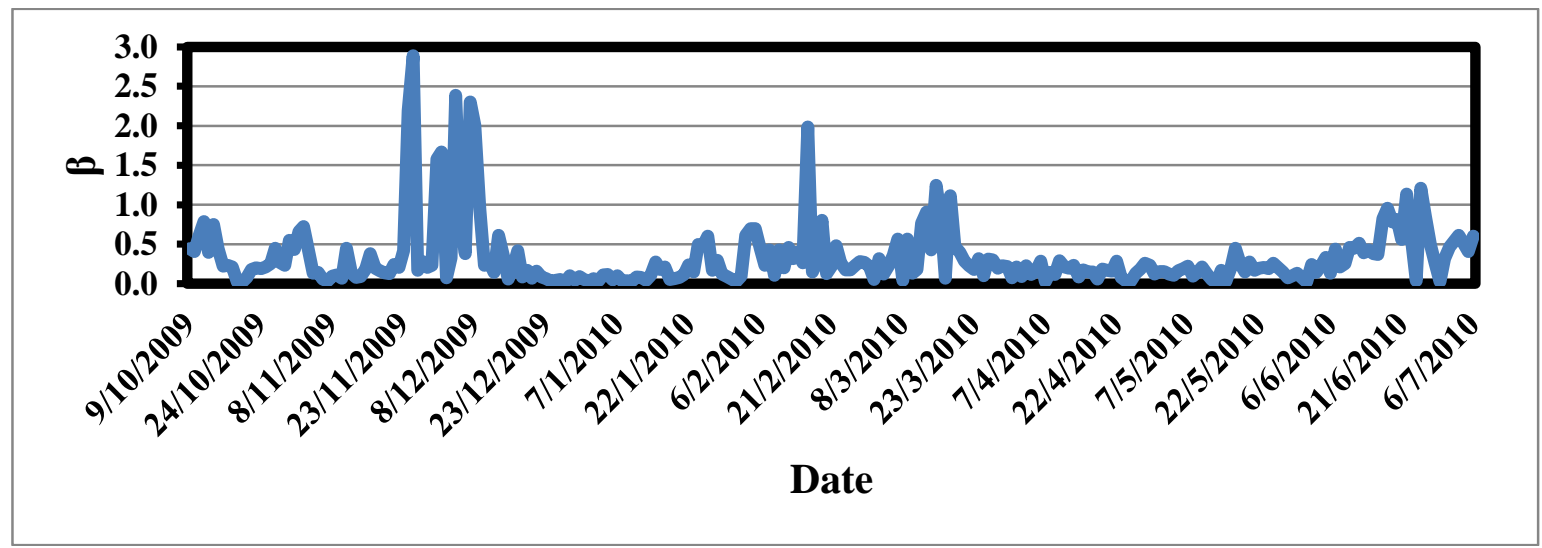

Figure 3: Daily variations of the Bowen Ratio.

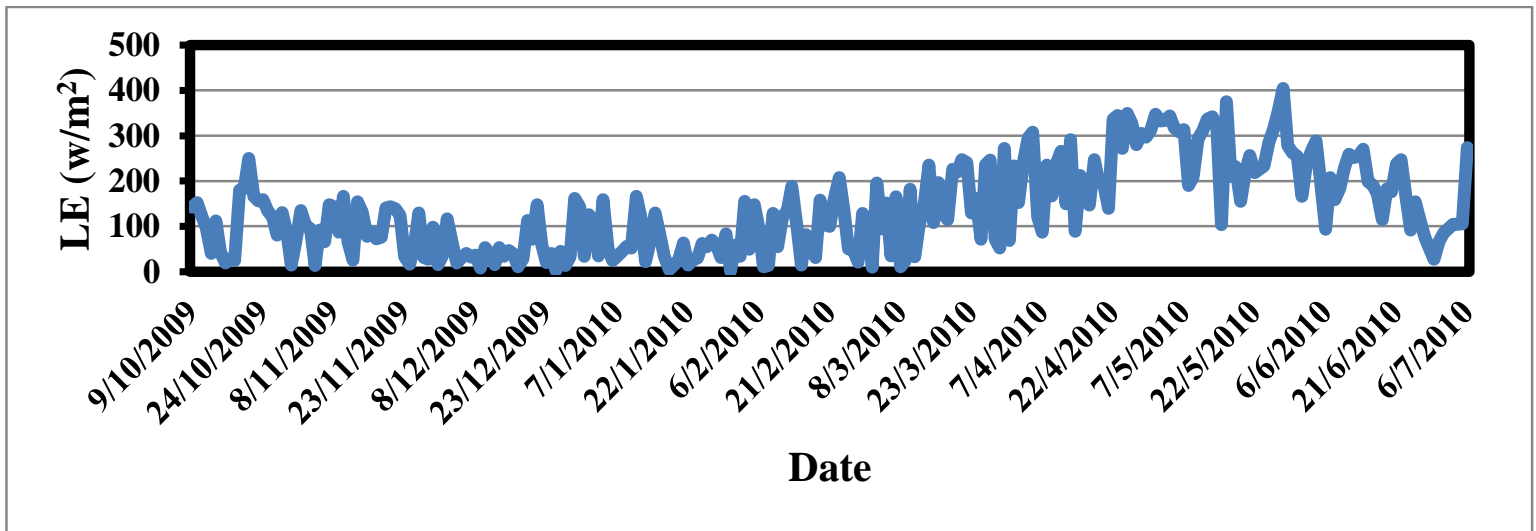

Figure 4: Daily variations of latent heat flux of evapotranspiration.

Average net radiation during the crop growing season was $198 \mathrm{~W} / \mathrm{m}^{2}$, while the soil heat flux, latent heat flux of evaporation and sensible heat flux values were determined as 19, 138 and $41 \mathrm{~W} / \mathrm{m}^{2}$, respectively. In the same period, averaged vapor pressure deficit and Bowen Ratio values were determined as $7 \mathrm{hPa}$ and 0.3 , successively. Meanwhile, maximum value of the average latent heat flux raised up to $405 \mathrm{~W} / \mathrm{m}^{2}$. Time series of the data derived from BREB calculations and filtration process are given with the figures below.

Following the related calculations, the energy balance components of the surface were determined and the distribution of the incoming energy into these components was established. Using the calculated LE $\left(\mathrm{W} / \mathrm{m}^{2}\right)$ values in the BREB approach for the 20092010 wheat growing season, daily $\mathrm{ET}_{\mathrm{a}}(\mathrm{mm})$ rates were determined and given in Figure 5. 


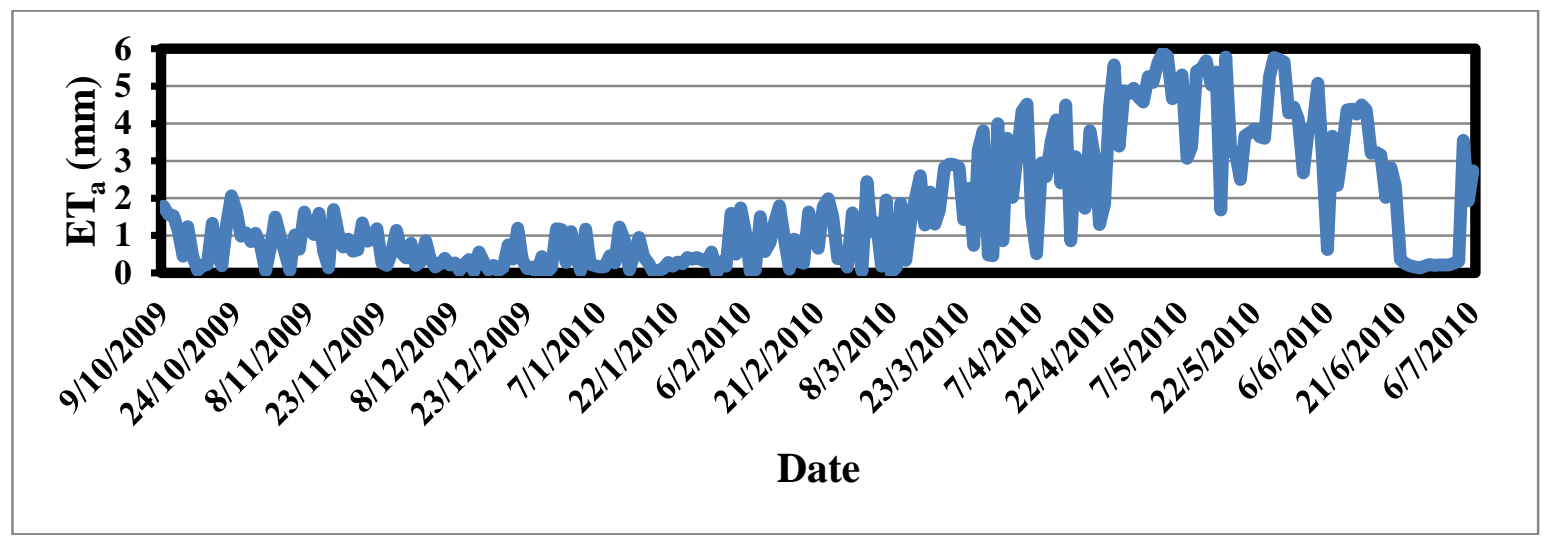

Figure 5 : Daily variation of the $\mathrm{ET}_{\mathrm{a}}$ values determined by the BREB Method.

Accordingly, total value of the $\mathrm{ET}_{\mathrm{a}}$ between sowing (9 October 2009) and harvest (6 July 2010) phases using the BREB Method are calculated as $465.3 \mathrm{~mm}$.

\section{Analysis of the Calculated EC Values}

Actual $\mathrm{ET}_{\mathrm{a}}(\mathrm{mm})$ values that were measured using the Eddy Covariance approach are given in the following Figure 6. Total $\mathrm{ET}_{\mathrm{a}}$ value between the aforementioned sowing and harvest dates were measured as 344.1 $\mathrm{mm}$ using the EC method. Within this period, daily mean $\mathrm{ET}_{\mathrm{a}}$ was determined as $1.27 \mathrm{~mm}$ with a standard deviation of 0.84 $\mathrm{mm}$.

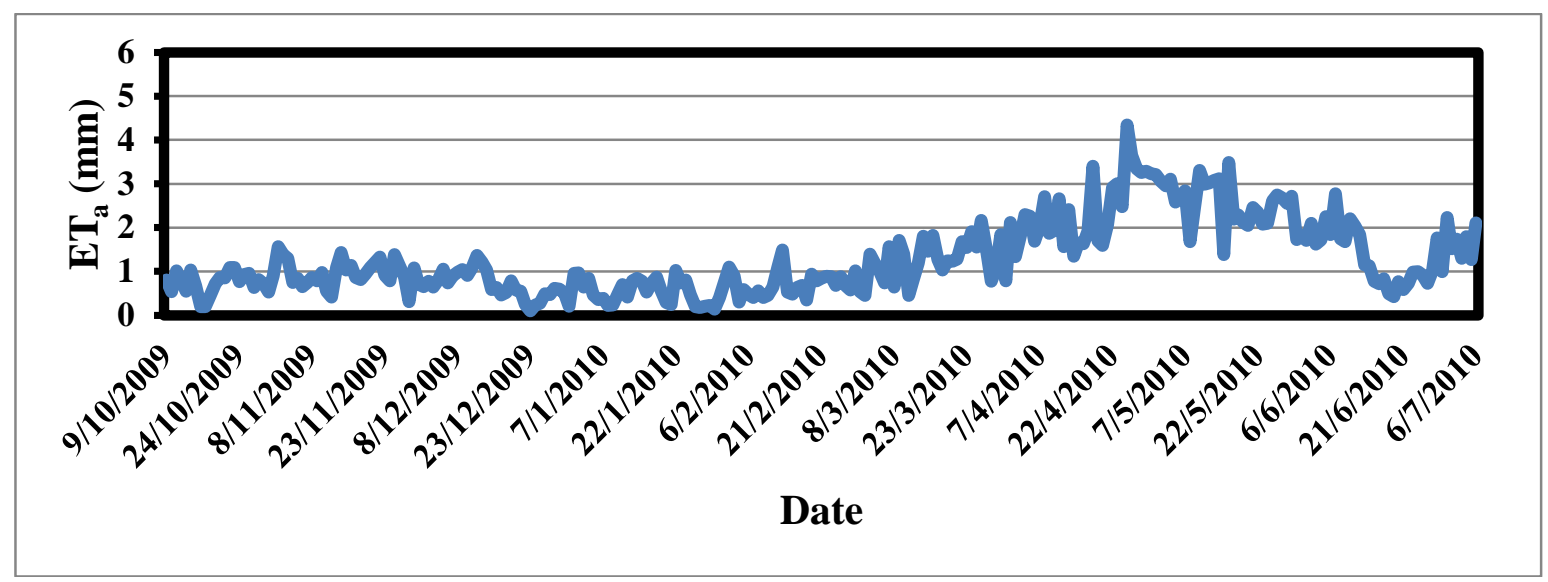

Figure 6: Time series of the $\mathrm{ET}_{\mathrm{a}}$ values obtained by EC approach.

Determination of the Relationships Between the BREB and EC Methods

Possible correlations between daily $\mathrm{ET}_{\mathrm{a}}$ values that were calculated using the BREB and EC methods were also investigated. As a result, a considerably high correlation coefficient has been found $(\mathrm{R}=0.84)$. Relationship between the results of the BREB and EC methods is shown with Figure 7. 


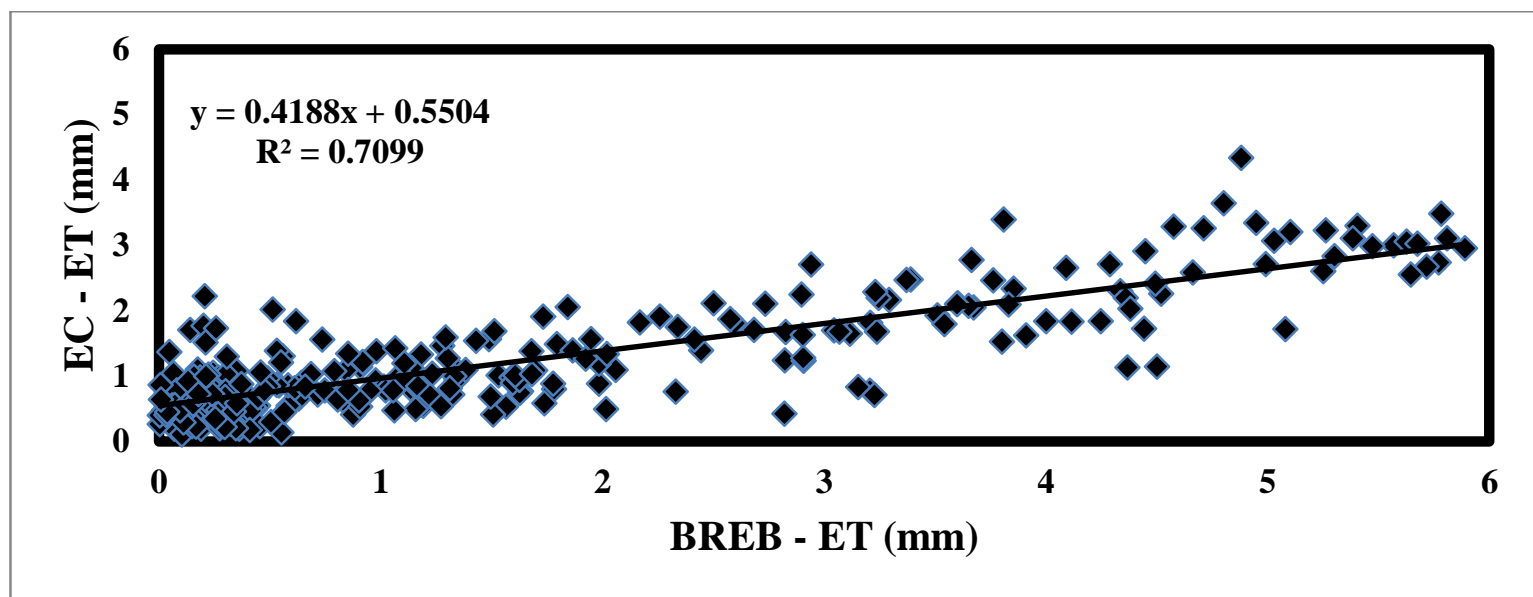

Figure 7: Relationship between the daily actual Evapotranspiration values obtained from the EC and BREB Methods.

Variation of $\mathrm{ET}_{\mathrm{a}}$ values during growing period obtained from these two different

approaches are given together in following Figure 8.

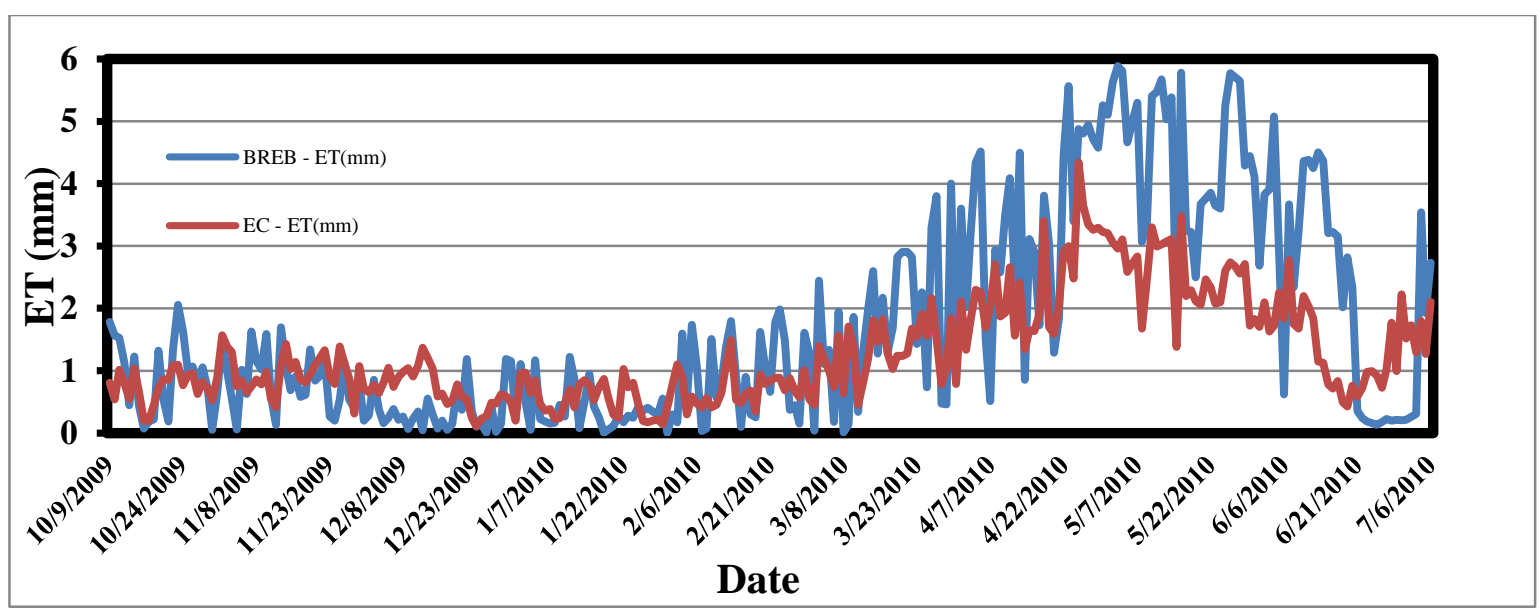

Figure 8: Time series of daily cumulated Evapotranspiration values measured by BREB and EC approaches.

\section{RESULTS AND CONCLUSION}

$\mathrm{ET}_{\mathrm{a}}$ values over a winter wheat field were determined by using the BREB and EC methods during a corresponding 271-day growing season in the Kirklareli city. Total ET $_{\mathrm{a}}$ using the BREB Method was determined as $465.3 \mathrm{~mm}$. Daily mean $\mathrm{ET}_{\mathrm{a}}$, which was calculated under consideration of total number of days in the growing season is $1.72 \mathrm{~mm}$. Data set consisting of daily data is represented with a standard deviation of $1.69 \mathrm{~mm}$. Maximum monthly $\mathrm{ET}_{\mathrm{a}}$ value occurred as $141 \mathrm{~mm}$ in May, whereas daily mean $\mathrm{ET}_{\mathrm{a}}$ was determined as $4.55 \mathrm{~mm}$ for the same month. Oppositely, lowest monthly total $\mathrm{ET}_{\mathrm{a}}$ 's occurred as December and January.

For the whole growing season, total $\mathrm{ET}_{\mathrm{a}}$ value determined by the EC Method was $344.1 \mathrm{~mm}$. Corresponding daily average $\mathrm{ET}_{\mathrm{a}}$ using the same method was $1.27 \mathrm{~mm}$ and the standard deviation of daily total $\mathrm{ET}_{\mathrm{a}}$ values was $1.27 \mathrm{~mm}$ again. On a monthly basis, maximum monthly total $\mathrm{ET}_{\mathrm{a}}$ was calculated as $79.45 \mathrm{~mm}$ in May according to the BREB approach. At the same time, daily mean $\mathrm{ET}_{\mathrm{a}}$ in May was $2.56 \mathrm{~mm}$. Detailed measurement process of the monthly total and daily average data that were obtained using the EC Method is given by Özkoca (2015). 
It is believed that the relatively lower values obtained from the EC method with regard to those of the BREB may be associated with several reasons such as lack of accurate measurements of the EC system which may be caused by rainy days, calm atmospheric conditions (low wind velocity) or days during which the air stream was not from the previously selected prevailing direction. On the other hand, unreliable outputs of the BREB method can be caused during sunrise and sunset periods and precipitation. Moreover, the data is also directly dependent to the selected type of the filtration method. In this connection, a broadly accepted filtration method throughout the global literature, for which the detailed application

\section{ACKNOWLEDGEMENTS}

This research was based on data within the frame of two TÜBİTAK 1001 projects. Also the Scientific Research Projects Unit (BAP) of the Istanbul Technical University have supported the study with a project (project code: 39017). The authors are therefore grateful to TÜBİTAK, Scientific Research

\section{REFERENCES}

Attarod, P., Aoki, M., Bayramzadeh, V. and Ahmadi, $\quad$ M.T. 2011. Micrometeorological observations above a Japanese red pine forest within the growing season. Turkish Journal of Agriculture, 35: 597-609.

Bezerra, B.G. 2012. Crop evapotranspiration and water use efficiency. Irrigation Systems and practices in Challenging Environments, 9: 57-76.

Bowen, I.S. 1926. The ratio of heat lossesby conduction and by evaporation from any water surface. Physical Review, 27: 779787.

Burba, G. and Anderson, D. 2013. A brief practical guide to Eddy Covariance flux measurements. Lincoln, pp. 6-28, LICOR Biosciences, Nebraska. progress was explained earlier, was used in this study. Regression analyses applied for the determination of the relationship between the BREB and EC methods showed a determination coefficient of $\mathrm{R}^{2}=0.71$. This ratio indicates a satisfactory relationship between EC and BREB approaches. Totally 117 precipitation days were recorded at the research field throughout the whole growing season (271 days). These intervals with precipitation can cause errors in the BREB and EC measurements. In the region, the month of June (especially it's second half) was severe rainy, so the associated effects on the calculations could be seen in all of the related graphs.

Projects Unit (BAP) of the Istanbul Technical University, TAGEM and Kırklareli Atatürk Soil, Water and Agricultural Meteorology Research Station Directorate (including all of their personel who supported the projects), together with Elif SEMIZZOGLU, Osman ÇAYLAK and all other scholars of the projects.

Cheng, C., Nnadi, F. and Liou, Y. 2014. Energy budget on various land use areas using reanalysis data in Florida. Advances in Meteorology, 2014: 1-13.

Dicken, U., Cohen, S. and Tanny, J. 2013. Examination of the Bowen ratio energy balance technique for evapotranspiration estimates in screenhouses. Biosystems Engineering, 114: 397-405.

Fritschen, L.J. and Simpson, J.R. 1989. Surface energy balance and radiation systems: general description and improvements. Journal of Applied Meteorology, 28: 680-689.

Fritschen, L.J. 2010. Accuracy of evapotranspiration determinations by the Bowen ratio method. Hydrological Science Journal, 2: 38-48.

Guo, X., Zhang, H., Kang, L., Du, J., Li, W. and Zhu, Y. 2007. Quality control and flux gap filling strategy for Bowen ratio 
method: revisiting the Priestley-Taylor evaporation model. Environmental Fluid Mechanics, 7: 421-437.

Inman-Bamber, N.G. and McGlinchey, M.G. 2003. Crop coefficient and wateruse estimates for sugarcane based on long-term Bowen Ratio energy balance measurements. Field Crops Research, 83: 125-138.

Khoomsab, K. and Khummongkol, P. 2011. Application of Bowen Ratio method for estimating fluxes of sulfate and nitrate aerosols. International Conference on Biology, Environment and Chemistry, Singapore, 2-4 November.

Oke, T.R. 1987. Boundary Layer Climates. NY, 2, pp. 435, John Wiley and Sons, New York.

Özkoca, Y. 2015. Determination of Energy Fluxes of Crops by using Micrometeorological Methods, İTÜ Graduate School of Sciende, Engineering and Technology, M. Sc. Thesis. pp 76.

Pauwels, V.R.N. and Samson, R. 2006. Comparison of different methods to measure and model actual evapotranspiration rates for a wet sloping grassland. Agricultural Water Management, 82: 1-24.

Poznikova, G., Trnka, M., Fischer, M., Orsag, M. and Zalud, Z. 2012. Applicability of Bowen Ratio Energy Balance method in fetch limited conditions. Mendelnet, Czech Republic, 21-22 November.

Shi, T., Guan, D., Wu, J., Wang, A., Jin, C. and Han, S. 2008. Comparison of methods for estimating evapotranspiration rate of dry forest canopy: Eddy Covariance, Bowen Ratio Energy Balance, and Penman-Monteith Equation. Journal of Geophysical Research, 113: 1-15.

Soares, J.M., De Azevedo, P.V. and Da Silva, B.B. 2007. Bowen Ratio-Energy Balance associated errors in vineyards under dripping irrigation. Revista Brasileira de Meteorologia, 22: 233-240.

Spittlehouse, D.L. and Black, T.A. 2010. Evaluation of the Bowen Ratio Energy
Balance Method for determining forest evapotranspiration. Atmosphere-Ocean, 2: 98-116.

Şaylan, L. 2000. The effects of the environmental factors on the evapotranspiration in different growth phases of soybean. Journal for Land Management, Food and Environment, Die Bodenkultur, 51: 127-134.

Şaylan, L., Bakanoğulları, F. and Çaldağ, B. 2012a. Investigation of the potential effects of climate change on crop growth by crop growth simulation models. Final report of the TÜBITAK Project, code: 1080567, pp. 261, March 2012, Istanbul.

Takagi, K., Kimura, R. and Şaylan, L. 2009. Variability of surface characteristics and energy flux patterns of sunn hemp under well-watered conditions. Theoretical and Applied Meteorology, 96: 261-273.

Todd, R.W., Evett, S.R. and Howell, T.A. 2000. The Bowen Ratio-Energy Balance method for estimating latent heat flux of irrigated alfalfa evaluated in a semi-arid, advective environment. Agricultural and Forest Meteorology, 103: 335-348.

Turkish State Meteorological Service, 2015. 2015, February 2). Statistics about cities. Accessed at: http://www.mgm.gov.tr

Ünlü, M., Kanber, R., Diker, K. and Steduto, P. 2001. Comparing cotton evapotranspiration estimated by micrometeorological and water budget methods. Turkish Journal of Agriculture, 25: 329-335.

Ünlü, M., Kanber, R. and Kapur, B. 2010. Comparison of soybean evapotranspirations measured by weighing lysimeter and Bowen Ratio Energy Balance method. African Journal of Biotechnology, 9: 4700-4713.

Ünlü, M., Kanber, R., Koç, D.L., Özekici, B., Kekeç, U. et. al., 2014. Irrigation scheduling of grapefruit trees in a Mediterranean environment throughout evaluation of plant water status and evapotranspiration. Turkish Journal of Agriculture and Forestry, 38: 908-915.

Wang, W., Xiao, W., Cao, C., Gao, Z., Hu, Z. Et. al., 2014. Temporal and spatial 
variations in radiation and energy balance across a large freshwater lake in China. Journal of Hydrology, 511: 811-824.

Wever, L.A., Flanagan, L.B. and Carlson, P.J. 2002. Seasonal and interannual variation in evapotranspiration, energy balance and surface conductance in northern temperate grassland. Agricultural and Forest Meteorology, 112: 31-49.

Xing, Z., Chow, L., Meng, F., Rees, H.W., Stevens, L. and Monteith, J. 2008. Validating evapotranspiration equation using Bowen Ratio in New Brunswick, Maritime, Canada. Sensors, 8: 412-428. 